\title{
Effect of High Temperature Supersonic Flow Conditions over Thermal Barrier Coating over a Flat Plate
}

\author{
Jeetendra Kumar Shah \\ Bachelor of Technology (Aeronautical Engg), School of Aeronautical Sciences, Hindustan University, Chennai, India
}

\begin{abstract}
For any supersonic missile, one of the most difficult task is to protect the missile's payload and internal components from the excessive heat generated during its flight due to the aerodynamic heating on missile surface. This can be done by applying a thermal barrier coating over missile surface. The performance of any supersonic missile coating can be judged by determining its erosion resistance and the amount of temperature reduction it can give in its substrate. Thus similar conditions were simulated on ground at Scramjet Test Facility in DRDL, Hyderabad. The coating was tested at extreme temperature condition for studying its performance. The shear stress acting at the plate centre was calculated to determine the erosion resistance of the coating. For determining the temperature performance, both bare plate as well as coated plate were tested at flight conditions. The temperature at their` bottom surfaces were measured by using three $\mathrm{K}$ type thermocouples. These temperature data were compared to determine the amount of temperature reduction given by thermal barrier coating. After conducting the tests, the thermal barrier coating was found to be efficient for the application on missile surface. This missile coating can protect missile's payload and its internal component thereby increasing missile's efficiency and life.
\end{abstract}

Keywords: Temperature, Thermal Barrier Coating, Flat Plate, DRDL, Supersonic Flow Conditions.

\section{INTRODUCTION}

For supersonic vehicle, theheat transfergenerally occurs at the surface because of aerodynamicviscositywhich ensures that the flow remains at zero speed relative to the body for a very thin layer of molecules at the surface. When fluid flow slows down itskinetic energygets converted into heat. In high speed flows, tremendous amount of heat is generated because of large kinetic energy of the fluid. When the flow is slowed to near zero speed, its kinetic energy gets converted into heat as a result of which the temperature increases and the gradient in the speed in a direction normal to the surface allows small scale mass transport effects to dissipate the temperature in the outward direction and thus the temperature at the surface is less than thestagnation temperature. These viscous dissipative effects to neighboring sub-layers make theboundary layerslow down via a non-isentropicprocess. Heat then conducts into the vehicle surface from the higher temperature air around it. The result is an increase in the temperature of vehicle surface and a loss of energy from the flow. Aerodynamic heating increases with the speed of the vehicle. It produces much less heating atsubsonic speedsbut becomes more important atsupersonic speeds.

When an object travels through air different factors such as skin friction, drag, shear force, viscosity of air etc. acts on the body. In the case of aircrafts, space shuttle and other objects such as missiles when these vehicles travel through fluids such as air, the kinetic energy of air gets converted into heat or thermal energy. This thermal energy is high in the cases of very high velocities. Thus the temperatures over a missile or any object travelling at a velocity of sound can produce a temperature of about $1600 \mathrm{~K}$ and more than that if we further increase the velocity. Thus this has become a major factor for limitation of speed in missiles, as the structural material cannot withstand that much amount of heat. In order to decrease this effect different methods are used among them TBC can effectively reduce the temperature.

For long range ballistic trajectories one of the most important and difficult phase of flight that designer must cope up with is the re-entry into the earth's atmosphere, wherein the aerodynamic heating associated with the high flight speed is intense. The air temperature in the boundary layer may reach values in the tens of thousands of degrees Fahrenheit which, combined with the high surface shear, promotes very great convective heat transfer to the surface. Heatabsorbent material or thermal barrier coatings must be provided to prevent destruction of the essential elements of missile. The surface shear plays an important role in the convective heat transfer to the surface therefore Reynold's number analogy can be used for the determination of skin friction coefficient and shear stress acting on the missile surface. However, the supersonic convective flow over missile surface can be considered as flow over a flat plate for the determination of skin friction coefficient and shear stress. 


\section{LITERATURE REVIEW}

Thermal Barrier Coatings are designed to protect metal structural components from extreme elevated temperatures, thereby reducing stress and fatigue and increasing the part's lifespan. In order to provide such a high level of protection, thermal barriers incorporate several key components. Every coating consists of four distinct layers, with each layer adding to the protective thermal properties and enabling the coating to form a unique thermal barrier.

Thermal barrier coatings typically consist of four layers: the metal substrate, metallic bond coat, thermally grown oxide, and ceramic topcoat. The ceramic topcoat is typically composed ofyttria-stabilized zirconia(YSZ) which is desirable for having very low conductivity while remaining stable at nominal operating temperatures

The application of thermal barrier coatings (TBCs) to missiles has facilitated the increase in performance and efficiency of missiles. The thermal barrier coatings can lower the temperature of missile surface which is exposed to very high temperature due to aerodynamic heating. TBCs are essentially multi-layered coating structures that consist of a bond coat that is applied to the substrate, a thermally grown oxide (TGO) and a ceramic topcoat, typically an yttria stabilized zirconia. The bond coat can be applied by either thermal spraying or by diffusion methods. The TGO is formed between the bond coat and the ceramic top coat, during the production of the coatings as a result of the oxidation of the bond coat and continues to grow throughout the life of the coating. Currently there are two basic production routes that are used for modern TBC systems; plasma spraying (PS) - in vacuum for the bond coat and air for the top coat or electron beam (EB) physical vapour deposition (PVD). However, TBCs are susceptible to various life limiting issues associated with their operating environment including, erosion, corrosion, oxidation, sintering and foreign object damage. This research is an experimental project and fully concentrated on the erosion resistance of TBC and the temperature reduction by TBC coating in its substrate.

The main objective was to generate high temperature supersonic flow and carry out the following tests on Thermal Barrier Coating:

1. Temperature reduction given by coating in its substrate.

2. Erosion test.

Conditions given to us: Stagnation temperature $=1500 \mathrm{~K}$, Exit pressure $=1.21$ bar, Mach No. at nozzle exit $=1.8$

\section{TEST SETUP FOR THE TESTING OF THERMAL BARRIER COATING}

4.1 Test plan:-The test was conducted at Scramjet Test Facility (STF) in DRDL, Hyderabad. The subscale vitiated air heater utilized for conducting erosion tests. The setup (Fig.4.1) consists of a Vitiated Air Heater (VAH), a circular to rectangular transition duct (CRTD), 2-D nozzle (facility nozzle) for Mach number 1.8 and the specimen plate holder. The vitiated air heater burns hydrogen, oxygen and air to generate the temperature conditions for testing. Oxygen replenishment was not done for present testing and high temperature conditions were generated burning hydrogen and air only. Air and hydrogen are fed into the heater through a system of high pressure storage cylinders, pressure regulating valve, ON/OFF ball valves and turbine flow meter. The mass flow rate of hydrogen and air to be fed into the heater is determined. Mixture of these gases is ignited in the heater with the help of spark plug. The setup installed at Scramjet Test Facility (STF) is shown in fig. 4.3. The block diagram of the Scramjet

Test facility is shown in figure 4.2

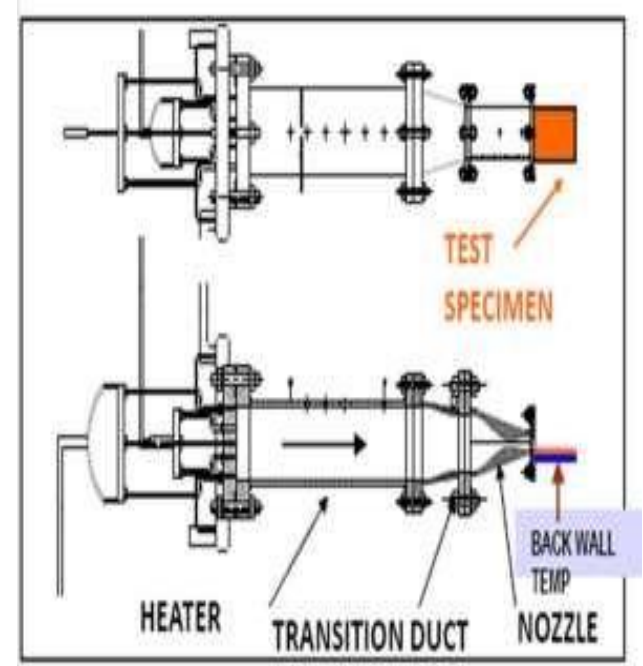

Fig.4.1 Test setup for conducting erosion test

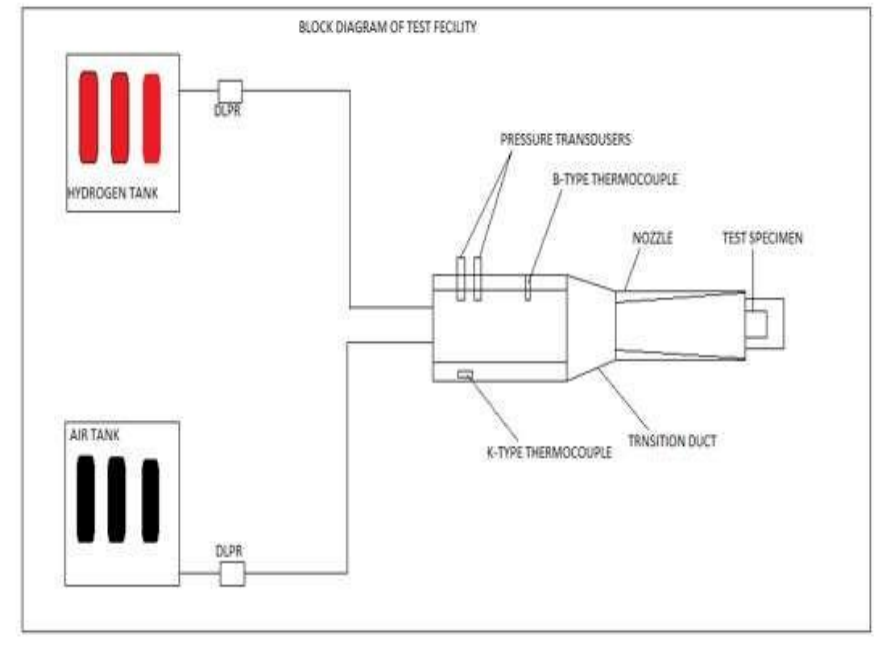

Fig.4.2. Scramjet Test Facility block diagram 
Hydrogen bank: -The Hydrogen cylinders are integrated to the master pipe through pipes and hoses. Handling of the hydrogen tanks is very important since hydrogen is highly flammable.

Air bank: - Air Bank consists of the pressurized air stored at 200psi. The dome loaded pressure regulator (DLPR) regulates the air at 200psi and maintains the amount of air entering into the Heater. The reason for using compressed air is to maintain the required mass flow rate in the heater.

Dome Loaded Pressure Regulator (DLPR):- A Dome loaded pressure regulator basically consists of Dome which has a considerable pressure in it. The DLPR is used to regulate the back pressure in the most of the cases. In our case we are using DLPR to regulate the pressure of air and hydrogen which flows into the heater

Turbine flow meter: - The purpose of turbine flow meter is to measure the velocity of the fluid (in our case it's the vitiated air coming out of the heater). The turbine flow meters consists of a turbine upstream to the flow, when the fluid hits the turbine it rotates with very high RPM. This rotational motion is measured and related to the flow velocity.

Heater: - The purpose of heater is to increase the temperature and velocity of the flow in order to simulate the conditions of missile in the desired altitude. In our case the conditions of air coming out of the heater should have: Temperature: $1500 \mathrm{~K}$ and Mass flow rate: $1.51 \mathrm{Kg} / \mathrm{sec}$

Challenges faced to generate mass flow rate of $1.51 \mathrm{Kg} / \mathrm{sec}$ at $1500 \mathrm{~K}$ :-

- The material has to withstand very temperature of $1500 \mathrm{~K}$.

- The time for the combustion of fuel is less.

- There is no extra chamber to mix the fuel, thus the fuel has to be mixed in the combustion chamber itself.

- The time required for mixing of the fuel for keeping it up to the desired stoichiometric point is less (stoichiometric point: it is the point which gives the ideal proportion of the fuel/air mixture for optimum combustion).

- Cooling mechanism must be used to maintain the optimum temperature of the heater.

- Overcoming the challenges faced:-

- Stainless Steel is used to withstand the temperature of $1500 \mathrm{~K}$ and very high amount of pressure in the heater.

- In our case hydrogen is used as the fuel since hydrogen has an autoignition temperature of $536^{\circ} \mathrm{C}$. Thus, using gaseous fuel over the liquid decreases the time for combustion and also decreases the carbon formation. The air coming out of the heater is a vitiated air since hydrogen also combines with oxygen in air to produce considerable amount of water molecules and other impurities.

- The heater is covered by water jackets in which continuous flow of water takes place thereby, reducing the amount of heat in the heater.

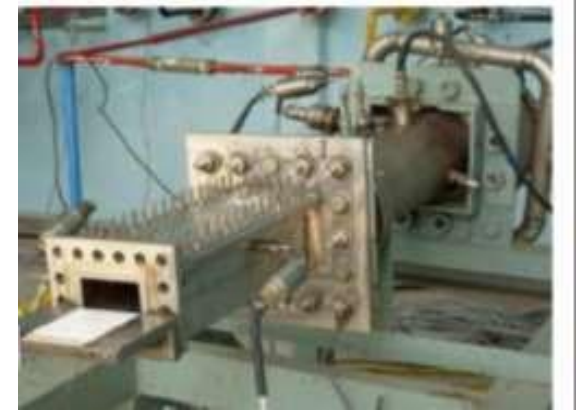

Fig.4.3. Test setup at Scramjet Test Facility
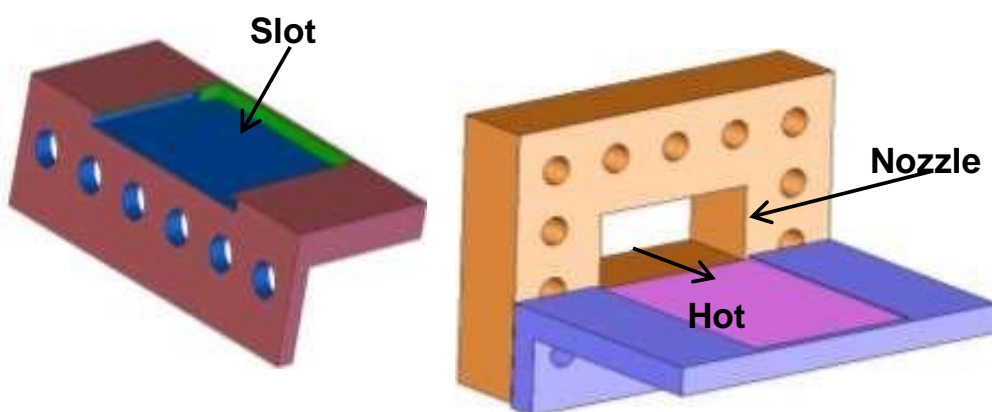

Fig.4.4. Specimen holder

The circular cross section of heater is converted into rectangular cross section using a circular to rectangular transition duct. A 2D nozzle is integrated with the heater and transition duct to produce a vitiated hot flow of Mach number 1.8. The nozzle exit cross section is $85 \mathrm{~mm} \times 40 \mathrm{~mm}$. Specimen plate holder (Fig.4.4) is integrated at the exit of facility nozzle. The plate holder is designed to hold the specimen in place during the test. Coated specimen has to be slid in the slot and the holder has to be attached to the nozzle exit of air heater by means of fasteners.

4.2 Specimen details:-To study the erosion resistance of the LDAM, specimen in the form of a flat plate of dimension $100 \mathrm{~mm} \times 120 \mathrm{~mm} \times 3 \mathrm{~mm}$ of Mild Steel was coated with LDAM. The details of specimen is mentioned in table 4.1.

\begin{tabular}{|l|l|l|}
\hline Specimen No. & Coating Material & Coating Thickness $(\mathrm{mm})$ \\
\hline 1. & Bare M.S. Plate & -- \\
\hline 2. & TBC & 2 \\
\hline
\end{tabular}


The specimen was fitted in flush with the nozzle exit of the air heater and airflow over the coating was tangential during the test 1 and 2, along with tangential flow the coating leading edges were also exposed to flow. These specimens were spot welded with 3 ' $\mathrm{K}$ ' type thermocouple to measure the back wall temperature of specimen during tests as shown in fig. 12.1

4.3 Measurement plan:-Strain gage based pressure sensors for static pressure measurement, type ' $B$ ' temperature sensors for flow stagnation temperature and type ' $\mathrm{K}$ ' sensors for outside surface temperature measurement, were used. Turbine flow meters with flow computers were used to measure mass flow rates of individual gases. The sensors used for measurements were calibrated and accuracy found to be within acceptable limits. NI - DAQ Lab view and SCADA system were used to acquire the pressure, temperature and flow data. TBC plate holders are designed to hold the coated specimen to the nozzle exit of the air heater

Table 4.2.Pressure measurement plan

\begin{tabular}{|l|l|l|}
\hline S. No. & Nomenclature & Location \\
\hline 1 & VAHP & Vitiated Air Heater pressure \\
\hline 2 & NOZ_EXIT & Exit of nozzle, static pressure \\
\hline 3 & H2_INJ & Hydrogen Injection Pressure \\
\hline 4 & AIR_INJ & Air Injection Pressure \\
\hline
\end{tabular}

Table 4.3.Temperature measurement plan

\begin{tabular}{|l|l|l|}
\hline S.No & Nomenclature & Location \\
\hline 1 & SMat01 & Type 'K' thermocouple, spot welded at the back wall of the specimen (Fig. 3) \\
\hline 2 & SMat02 & Type ' $K$ ' thermocouple, spot welded at the back wall of the specimen (Fig. 3) \\
\hline 3 & SMat03 & Type ' $K$ ' thermocouple, spot welded at the back wall of the specimen (Fig. 3) \\
\hline
\end{tabular}

Table 4.4.Flow measurement plan

\begin{tabular}{|l|l|l|}
\hline S. No. & Nomenclature & Location \\
\hline 1. & Air flow rate & Air feed system \\
\hline 2. & Hydrogen flow rate & Hydrogen feed system \\
\hline
\end{tabular}

Reason for using $\mathrm{K}$ type thermocouple to measure surface temperature and B type thermocouple to measure gas flow temperature in the heater:-Different types of thermocouples have different ranges of operation for an example a ' $\mathrm{B}$ ' type thermocouple has a rage of $870^{\circ} \mathrm{C}$ to $1700^{\circ} \mathrm{C}$ whereas a ' $\mathrm{K}$ ' type thermocouple has a range from $293^{\circ} \mathrm{C}$ to $1260^{\circ}$ C. Since the temperature of the skin will be less in comparison with the gas flow temperature therefore, different thermocouples are used for the measurement purpose. Different types of thermocouples and their wide ranges of operation are shown in figure 4.6.

\begin{tabular}{|c|c|c|c|c|c|c|}
\hline \multicolumn{7}{|c|}{ TOLERANCE OF THERMOCOUPLES } \\
\hline \multirow[b]{2}{*}{ ANSVASTM } & \multicolumn{3}{|c|}{ C } & \multicolumn{3}{|c|}{$\mathrm{F}$} \\
\hline & Temperature Range & Standard & Special & Temperature Range & Standard & Special \\
\hline$T$ & $\begin{array}{l}-200^{\circ} \text { to }-6 r \\
-67 \text { to }-62^{\circ} \\
-62^{\circ} \text { to } 125^{\circ} \\
125^{\circ} \text { to } 133^{\circ} \\
133^{3} \text { to } 370^{\circ}\end{array}$ & $\begin{array}{l} \pm 1.5 \% \mathrm{~T} \\
\pm 1 \\
\pm 1 \\
\pm 1 \\
\pm 0.75 \% \mathrm{~T}\end{array}$ & $\begin{array}{l} \pm 0.8 \% \mathrm{~T}^{*} \\
\pm 0.8 \% \mathrm{~T}^{*} \\
\pm 0.5 \\
\pm 0.4 \% \mathrm{~T} \\
\pm 0.4 \% \mathrm{~T}\end{array}$ & $\begin{array}{l}-328^{\circ} \text { to }-88^{\circ} \\
-88^{\circ} \text { to }-80^{\circ} \\
-80^{\circ} \text { to } 257 \\
25 T^{\circ} \text { to } 272^{\circ} \\
272^{\circ} \text { to } 700^{\circ}\end{array}$ & $\begin{array}{l} \pm 1.5 \%(\mathrm{~T}-32) \\
\pm 1.8^{\circ} \\
\pm 1.8^{\circ} \\
\pm 1.8^{\circ} \\
\pm 0.75 \%(\mathrm{~T}-32)\end{array}$ & $\begin{array}{l} \pm 0.8 \%(T-32)^{*} \\
\pm 0.8 \%(T-32)^{*} \\
\pm 0.9^{\circ} \\
\pm 0.4 \%(T-32) \\
\pm 0.4 \%(T-32)\end{array}$ \\
\hline J & $\begin{array}{l}\sigma^{\circ} \text { to } 275^{\circ} \\
275^{\circ} \text { to } 293^{\circ} \\
293^{\circ} \text { to } 760^{\circ}\end{array}$ & $\begin{array}{l} \pm 2.2 \\
\pm 2.2 \\
\pm 0.75 \% \mathrm{~T}\end{array}$ & $\begin{array}{l}=1.1^{\circ} \\
\pm 0.4 \% \mathrm{~T} \\
\pm 0.4 \% \mathrm{~T}\end{array}$ & $\begin{array}{l}32^{\circ} \text { to } 527^{\circ} \\
527 \text { to } 560^{\circ} \\
560^{\circ} \text { to } 1400^{\circ}\end{array}$ & $\begin{array}{l} \pm 3.96^{\circ} \\
\pm 3.96^{\circ} \\
\pm 0.75 \%(\pi-32)\end{array}$ & $\begin{array}{l} \pm 1.98^{\circ} \\
\pm 0.4 \%(\mathrm{~T}-32) \\
\pm 0.4 \%(\mathrm{~T}-32)\end{array}$ \\
\hline $\mathbf{E}$ & $\begin{array}{l}-200^{\circ} \text { to }-170^{\circ} \\
-170^{\circ} \text { to } 250^{\circ} \\
250^{\circ} \text { to } 340^{\circ} \\
340^{\circ} \text { to } 870^{\circ}\end{array}$ & $\begin{array}{l} \pm 1 \% \mathrm{~T} \\
\pm 1 . T \\
\pm 1 . T \\
\pm 0.5 \% T\end{array}$ & $\begin{array}{l} \pm 1 \% \\
\pm 1 \% \\
\pm 0.4 \% \mathrm{~T} \\
\pm 0.4 \% \mathrm{~T}\end{array}$ & $\begin{array}{l}-328^{\prime} \text { to }-274^{\prime} \\
-274^{\prime} \text { to } 482^{\prime} \\
482^{\prime} \text { to } 644^{\prime} \\
644^{\prime} \text { to } 1600^{\prime}\end{array}$ & $\begin{array}{l} \pm 1 \%(T-32) \\
\pm 3.06^{\circ} \\
\pm 3.06^{\circ} \\
\pm 0.5 \%(T-32)\end{array}$ & $\begin{array}{l} \pm 1.8^{\circ} \\
\pm 1.8^{\circ} \\
=0.4 \%(T-32) \\
\pm 0.4 \%(T-32)\end{array}$ \\
\hline K & $\begin{array}{l}-200^{\circ} \text { to }-110^{\circ} \\
-100^{\circ} \text { to } 0^{\circ} \\
0^{\circ} \text { to } 275^{\circ} \\
275^{\circ} \text { to } 293^{\circ} \\
293^{\circ} \text { to } 1260^{\circ}\end{array}$ & $\begin{array}{l} \pm 2 \% \mathrm{~T} \\
\pm 2.2 \\
\pm 2.2 \\
\pm 2.2 \\
\pm 0.75 \% \mathrm{~T}\end{array}$ & $\begin{array}{l}- \\
\pm 1.1 \\
\pm 0.4 \% \mathrm{~T} \\
=0.4 \% \mathrm{~T}\end{array}$ & $\begin{array}{l}-328^{\circ} \text { to }-166^{\circ} \\
-166^{\circ} \text { to } 32^{\prime} \\
32^{\circ} \text { to } 527 \\
527^{\circ} \text { to } 560^{\circ} \\
560^{\circ} \text { to } 2300^{\circ}\end{array}$ & $\begin{array}{l} \pm 2 \%(\mathrm{~T}-32) \\
\pm 3.96^{6} \\
\pm 3.96 \\
\pm 3.96 \\
\pm 0.75 \%(\pi-32)\end{array}$ & $\begin{array}{l}- \\
\pm 1.98 \\
\pm 0.4 \%(\mathrm{~T}-32) \\
\pm 0.4 \%(\mathrm{~T}-32)\end{array}$ \\
\hline $\mathbf{N}$ & $\begin{array}{c}0^{\circ} \text { to } 275^{\prime} \\
275^{\circ} \text { to } 293^{\circ} \\
293^{\prime} \text { to } 1250^{\circ}\end{array}$ & $\begin{array}{l} \pm 2.2 \\
\pm 2.2 \\
\pm 0.75 \% \mathrm{~T}\end{array}$ & $\begin{array}{l} \pm 1.1^{\circ} \\
=0.4 \% \mathrm{~T} \\
\pm 0.4 \% \mathrm{~T}\end{array}$ & $\begin{array}{l}32^{\circ} \text { to } 527^{\circ} \\
527 \text { to } 560^{\circ} \\
560^{\circ} \text { to } 2300^{\circ}\end{array}$ & $\begin{array}{l} \pm 3.96 \\
\pm 3.96 \\
\pm 0.75 \%(\pi-32)\end{array}$ & $\begin{array}{l} \pm 1.98 \\
=0.4 \%(T-32) \\
\pm 0.4 \%(T-32)\end{array}$ \\
\hline Ror $s$ & $\begin{array}{r}0^{\circ} \text { to } 1260^{\circ} \\
1260^{\circ} \text { to } 1480^{\circ}\end{array}$ & $\begin{array}{l} \pm 1.5 \\
\pm 0.25 \% \mathrm{~T}\end{array}$ & $\begin{array}{l} \pm 0.6 \\
\pm 0.1 \% \mathrm{~T}\end{array}$ & $\begin{array}{r}32^{\circ} \text { to } 1112^{\circ} \\
1112^{\circ} \text { to } 2700^{\circ}\end{array}$ & $\begin{array}{l} \pm 2.7 \\
\pm 0.25 \%(\mathrm{~T}-32)\end{array}$ & $\begin{array}{l} \pm 1.08 \\
\pm 0.1 \%(\tau-32)\end{array}$ \\
\hline$B$ & $870^{\circ}$ to $1700^{\circ}$ & $\pm 0.5 \% \mathrm{~T}$ & $\pm 0.25 \%$ & $1600^{\circ}$ to $3100^{\circ}$ & $\pm 0.5 \%(\pi-32)$ & $\pm 0.25 \%(\pi-32)$ \\
\hline $\mathrm{C}^{*}$ & $\begin{array}{c}0^{\circ} \text { to } 426 \\
426 \text { to } 2315\end{array}$ & $\begin{array}{l} \pm 4.4^{\circ} \\
\pm 1 \% \mathrm{~T}\end{array}$ & $\overline{-}$ & $\begin{array}{l}32^{\circ} \text { to } 800^{\circ} \\
800^{\circ} \text { to } 4200^{\circ}\end{array}$ & $\begin{array}{l} \pm 8 \\
\pm 1 \%(T-32)\end{array}$ & $\overline{-}$ \\
\hline
\end{tabular}

Fig.4.6. Tolerance of thermocouples 
4.4 Firing sequence:- The sequence for starting and ending of different feed system and data recording is shown in table 4.5. Also the feed system duration is shown in fig.4.7. From fig.4.7 and table 4.5, it is clear that the hot flow of air is started at $\mathrm{t}=0$ (Spark Ignition on) and stopped at $\mathrm{t}=16 \mathrm{~s}$ (Heater hydrogen off). Thus the test was aimed for 16s. Table 4.5.Typical firing sequence

\begin{tabular}{|l|l|l|}
\hline S. No. & Event & Time $(\mathbf{s e c})$ \\
\hline 1 & DATA ACQUISATION ON & -20 \\
\hline 2 & AIR ON & -7 \\
\hline 3 & HEATER HYDROGEN ON & -4 \\
\hline 4. & SPARK IGNITION ON & 0 \\
\hline 5 & SPARK IGNITION OFF & 8 \\
\hline 6 & HEATER HYDROEGN OFF & 16 \\
\hline 7 & AIR OFF & 43 \\
\hline 8 & DATA ACQUISATION OFF & 48 \\
\hline
\end{tabular}

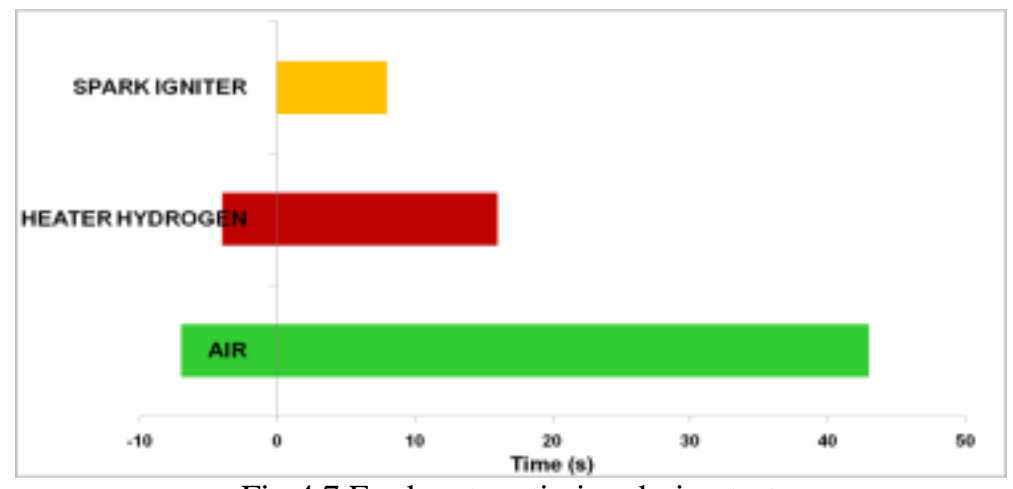

Fig.4.7.Feed system timing during test

4.5 Typical pressure data:-Fig. 4.8(a) shows the heater and nozzle exit static pressure during the test whereas the fig. 4.8(b) shows the typical air and hydrogen injection pressures. The hot flow is indicated in the figure, which is the same as the test duration

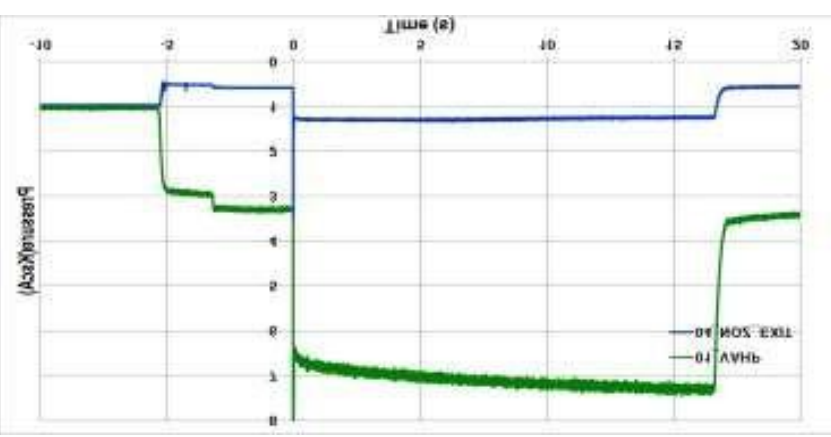

Fig.4.8 (a).Heater and nozzle exit pressure

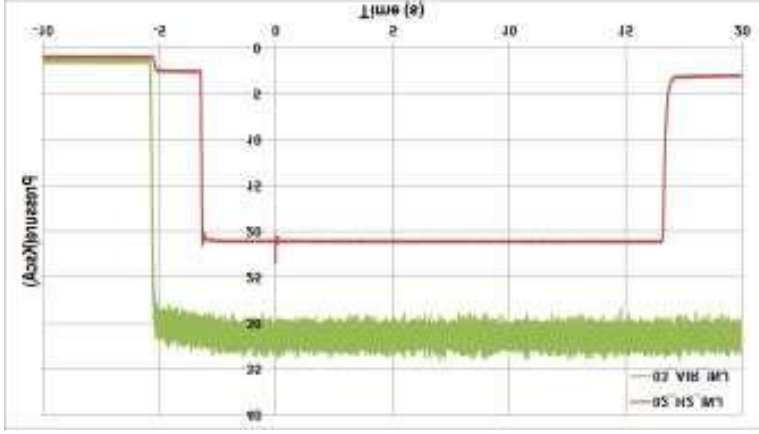

Fig.4.8 (b).Air and hydrogen injection pressure

\section{ASSUMPTIONS}

1. The nozzle is considered to be a Divergent nozzle with constant change in the area (keeping $\theta$ as constant). The area change is assumed to be constant for the simplification of our calculation.

2. The specific heat constant is taken as constant $(\gamma=1.3)$. The specific heat constant in the nozzle will keep on changing with the change in temperature. The $\mathrm{C}_{\mathrm{P}}$ and $\mathrm{C}_{\mathrm{V}}$ both increases along the nozzle but the specific heat constant $(\gamma)$ decreases as the temperature decreases due to the expansion of gases in the nozzle. Calculation of specific heat constant at every segment is very difficult thus, the specific heat constant is assumed to be a constant

3. The flow in the heater and nozzle is considered to be isentropic flow. Since it is complicated to calculate the various flow relations for an entire flow, a constant volume is considered. It is also been considered that the temperature is not added or escaped thus being an adiabatic and reversible process. Hence isentropic flow is assumed for the calculation of various flow parameters. 
4. Exit pressure is taken as 1.2 bar to prevent the boundary layer separation and to maintain a smooth exit flow. Since the simulation is done on the ground level, the pressure at the ground level where the test has been conducted is 1.2 bar. 1.2 bar exit pressure is taken into consideration so as to prevent certain losses such as boundary layer separation and to prevent over expansion condition. The exit pressure is maintained to be equal with the ground level pressure

5. The frictional losses in the nozzle are neglected. For the project, our aim is to produce supersonic flow at Mach No. 1.8 thus, the frictional losses are omitted since they are very less.

\section{SOLVING METHODOLOGY}

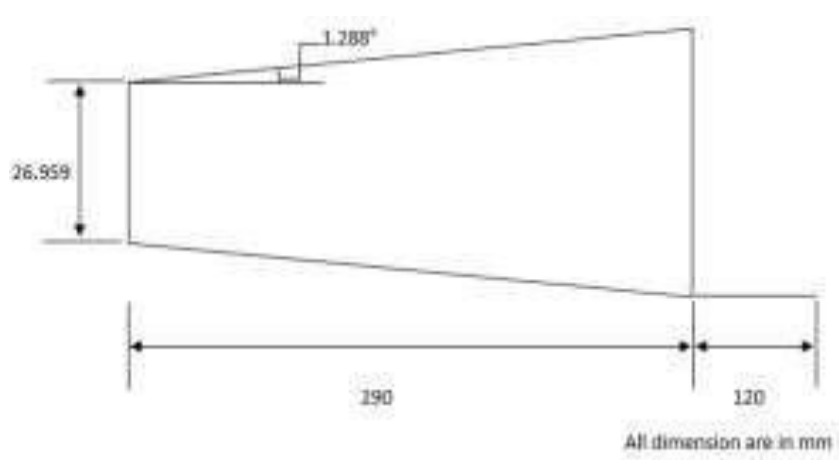

Fig.6.1.Simplified setup considered for analysis

1. The diverging part of the nozzle is divided into segments of $10 \mathrm{~mm}$ length as shown in Fig.6.1.

2. Mach number for various stations along the length of nozzle is obtained from area ratio by using area variation of nozzle.

3. Local values of static temperatures are calculated by taking stagnation temperature measured in VAH and local values of ratio of specific heats obtained from area ratio.

4. Local velocities are calculated as, local $=M_{\text {local }} \times(\gamma . R . T)^{0.5}$

Local value of Gas constant ' $\mathrm{R}$ ' is used for calculation. The value of $\mathrm{R}=\frac{8314}{26.6}=312.556 \mathrm{~J} / \mathrm{Kg} \mathrm{K}$

5. Using local values of static temperatures and velocities, average values for the segments are calculated.

6. Average Mach numbers for the segments are calculated using average static temperatures and velocities.

7. Average values of densities for the segments are calculated in a similar way. ${ }^{T} 1.5$

8. Viscosity is calculated using Sutherland's Law considering average $\mathrm{T}_{\text {static }} \mu=1.46 \times 10^{-6}$ ( $T+111$

9. Reynolds number for each segment is calculated considering average values of density, velocity and viscosity for the segment. The characteristic dimension for each segment is the segment length of $10 \mathrm{~mm}$.

10. Cumulative Reynolds number at the exit of nozzle, enozzleexit $=R_{e 1}+R_{e 2}+R_{e 3}+\ldots \ldots \ldots \ldots+R_{e 29}$

11. Reynolds number at the centre of the plate is calculated as follows: $R_{\text {eplatecentre }}=\rho_{\text {- }}$ nozzleexit ${ }_{\mu}$ nozzle $\times$ Vnozzleexitexit $\times V 2+$ Renozzleexit

12. The nozzle exit Mach number is 1.8. Skin friction coefficient $\left(C_{f x}\right)$ for adiabatic wall is obtained from heat and mass transfer data book, using nozzle exit Mach number and Reynolds number at the centre of the plate.

13. Shear Stress at plate centre is calculated as follows: $\tau=C_{f x} \times 1 / 2 \times \rho_{\text {nozzleexit }} \times V^{2}{ }_{\text {nozzleexit }}$

\section{CALCULATION OF FLOW PARAMETERS}

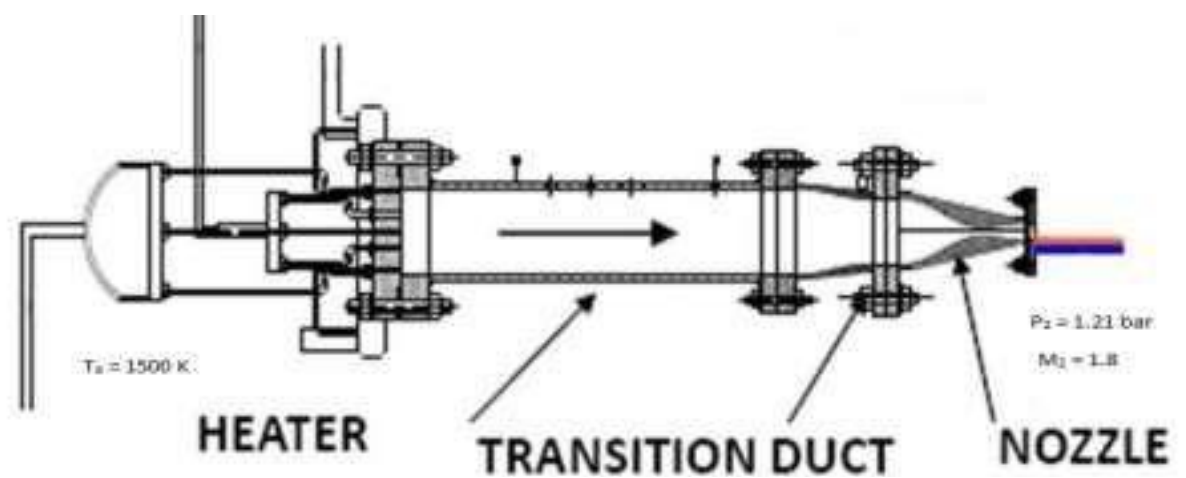

Fig.7.1.Test setup with various conditions 
The test conditions are as follows:-

Total temperature $\left(\mathrm{T}_{\mathrm{o}}\right)=1500 \mathrm{~K}$, Exit Mach No. $\left(\mathrm{M}_{2}\right)=1.8$, Pressure at nozzle exit $\left(\mathrm{P}_{2}\right)=1.21 \mathrm{bar}$,

Specific heat constant $(\gamma)=1.3$, From Temperature-Mach no. relation, ${ }^{T} O^{2}=1+M_{22} \frac{1}{(\gamma-21)}$ Where, $\mathrm{T}_{2}=$ Temperature at nozzle exit, $\overline{1500} \quad 1+1.8^{2}\left(\frac{1.3-1}{2}\right)_{T^{2}}=\quad 1 \quad, \mathrm{~T}_{2}=1009.5 \mathrm{~K}$.

From pressure-Temperature relation, ${ }^{2}=\left(T^{2}\right)^{\gamma^{-1}}$, Where, $\mathrm{P}_{\mathrm{O}}=$ Total pressure, so ${ }^{1.21}=(), \mathrm{P}_{\mathrm{O}}=\frac{1009.5}{1500}{ }^{\frac{1.3}{0.3}} \gamma^{6.773}$ bar

$$
\text { PO TO }
$$

Now, by using gas tables:- At $\mathrm{M}_{2}=1.8$ and $\gamma=1.3, \mathrm{~A}_{2} / \mathrm{A}^{*}=1.484$

Where, $A_{2}=$ Area of nozzle exit, $A^{*}=$ Area of throat, Area of throat $\left(A_{2}\right)=85 * 40=3400 \mathrm{~mm}^{2}$

Therefore, by using area ratio, $\quad \frac{3400}{A^{*}}=1.484, \quad \mathrm{~A}^{*}=2291.105 \mathrm{~mm}^{2}$

Now, $\mathrm{A}^{*}=$ width $*$ Height,$\quad$ Here, Width $=85 \mathrm{~mm}$, On substitution, $2291.105=85 * \mathrm{~h}, \quad \mathrm{~h}=26.954 \mathrm{~mm}$.

$$
(m)={ }^{A} T_{O} \sqrt{\frac{-}{R}} M_{2}\left(1+M_{2} \frac{}{2}\right)^{\frac{-(\gamma+1)}{\underline{(n+1)}}}
$$

Now, the mass flow at nozzle exit condition). $\sqrt{ }$

\section{TABULATION OF VALUES}

The values at every section are calculated and then tabulated as follows:-

\begin{tabular}{|l|l|l|l|l|l|l|}
\hline $\begin{array}{l}\text { Distance } \\
\text { from the } \\
\text { throat } \\
(\mathrm{mm})\end{array}$ & Area ratio & Mach No. & $\frac{\mathrm{T}}{\mathrm{T}_{0}}$ & $\begin{array}{l}\text { Local Static } \\
\text { Temperature, } \\
\left.\mathrm{T}{ }^{\circ} \mathrm{C}\right)\end{array}$ & $\frac{\mathrm{P}}{\mathrm{P}_{0}}$ & $\begin{array}{l}\text { Local } \\
\text { Static } \\
\text { Pressure, } \\
\mathrm{P} \text { (bar) }\end{array}$ \\
\hline 10 & 1.0166 & 1.1424 & 0.8362 & 1254.40 & 0.4607 & 3.120 \\
\hline 20 & 1.0327 & 1.2019 & 0.8219 & 1232.85 & 0.4274 & 2.894 \\
\hline 30 & 1.0455 & 1.2394 & 0.8127 & 1219.05 & 0.4071 & 2.757 \\
\hline 40 & 1.0625 & 1.2822 & 0.8022 & 1203.30 & 0.3847 & 2.605 \\
\hline 50 & 1.0795 & 1.3196 & 0.7929 & 1189.35 & 0.3658 & 2.477 \\
\hline 60 & 1.0965 & 1.3533 & 0.7845 & 1176.75 & 0.3493 & 2.365 \\
\hline 70 & 1.1135 & 1.3842 & 0.7767 & 1165.05 & 0.3346 & 2.266 \\
\hline 80 & 1.1305 & 1.4128 & 0.7695 & 1154.25 & 0.3214 & 2.176 \\
\hline 90 & 1.1475 & 1.4395 & 0.7628 & 1144.20 & 0.3094 & 2.095 \\
\hline 100 & 1.1645 & 1.4650 & 0.7564 & 1134.60 & 0.2983 & 2.020 \\
\hline 110 & 1.1835 & 1.4918 & 0.7497 & 1124.55 & 0.2870 & 1.943 \\
\hline 120 & 1.2001 & 1.5141 & 0.7441 & 1116.15 & 0.2778 & 1.881 \\
\hline 130 & 1.2168 & 1.5355 & 0.7387 & 1108.05 & 0.2692 & 1.823 \\
\hline 140 & 1.2335 & 1.5562 & 0.7335 & 1100.25 & 0.2611 & 1.768 \\
\hline 150 & 1.2502 & 1.5760 & 0.7285 & 1092.75 & 0.2535 & 1.716 \\
\hline 160 & 1.2669 & 1.5951 & 0.7237 & 1085.55 & 0.2463 & 1.668 \\
\hline 170 & 1.2836 & 1.6136 & 0.7191 & 1078.65 & 0.2396 & 1.622 \\
\hline 180 & 1.3002 & 1.6314 & 0.7147 & 1072.05 & 0.2332 & 1.579 \\
\hline 190 & 1.3169 & 1.6488 & 0.7103 & 1065.45 & 0.2271 & 1.538 \\
\hline 200 & 1.3336 & 1.6657 & 0.7061 & 1059.15 & 0.2214 & 1.499 \\
\hline 210 & 1.3503 & 1.6821 & 0.7020 & 1053.00 & 0.2159 & 1.462 \\
\hline 220 & 1.3670 & 1.6981 & 0.6980 & 1047.00 & 0.2106 & 1.426 \\
\hline 230 & 1.3837 & 1.7137 & 0.6942 & 1041.30 & 0.2056 & 1.392 \\
\hline 240 & 1.4004 & 1.7289 & 0.6904 & 1035.60 & 0.2008 & 1.360 \\
\hline 250 & 1.4171 & 1.7437 & 0.6867 & 1030.05 & 0.1963 & 1.329 \\
\hline 260 & 1.4337 & 1.7581 & 0.6832 & 1024.80 & 0.1919 & 1.299 \\
\hline 270 & 1.4504 & 1.7723 & 0.6797 & 1019.55 & 0.1877 & 1.271 \\
\hline 280 & 1.4671 & 1.7862 & 0.6763 & 1014.45 & 0.1837 & 1.224 \\
\hline 290 & 1.4837 & 1.7997 & 0.6730 & 1009.50 & 0.1798 & 1.217 \\
\hline & & & & & & \\
\hline
\end{tabular}

\begin{tabular}{|l|l|l|l|l|}
\hline $\begin{array}{l}\text { Distance from the } \\
\text { throat }(\mathrm{mm})\end{array}$ & $\begin{array}{l}\text { Dynamic } \\
\text { Viscosity, } \\
(\mathrm{Kg} / \mathrm{m} \mathrm{sec})\end{array}$ & $\begin{array}{l}\text { Local velocity, } \\
(\mathrm{m} / \mathrm{sec})\end{array}$ & $\begin{array}{l}\text { Local density, } \\
\left(\mathrm{Kg} / \mathrm{m}^{3}\right)\end{array}$ & $\begin{array}{l}\text { Reynold's } \\
\text { Number, } \mathrm{R}_{\mathrm{o}}\end{array}$ \\
\hline 10 & $4.7506 \times 10^{-5}$ & 815.5914 & 0.7957 & 136607.181 \\
\hline 20 & $4.7029 \times 10^{-5}$ & 850.6659 & 0.7510 & 135847.160 \\
\hline 30 & $4.6721 \times 10^{-5}$ & 872.2835 & 0.7235 & 135077.872 \\
\hline 40 & $4.6351 \times 10^{-5}$ & 896.5578 & 0.6926 & 133973.987 \\
\hline 50 & $4.6045 \times 10^{-5}$ & 917.3450 & 0.6663 & 132749.553 \\
\hline 60 & $4.5766 \times 10^{-5}$ & 935.7757 & 0.6430 & 131476.015 \\
\hline 70 & $4.5499 \times 10^{-5}$ & 952.3722 & 0.6222 & 130253.889 \\
\hline 80 & $4.5251 \times 10^{-5}$ & 967.5339 & 0.6031 & 128962.469 \\
\hline 90 & $4.5018 \times 10^{-5}$ & 981.5179 & 0.5858 & 127720.730 \\
\hline 100 & $4.4795 \times 10^{-5}$ & 994.7057 & 0.5696 & 126481.017 \\
\hline 110 & $4.4562 \times 10^{-5}$ & 1008.4060 & 0.5527 & 125072.033 \\
\hline 120 & $4.4365 \times 10^{-5}$ & 1019.6507 & 0.5391 & 123902.556 \\
\hline 130 & $4.4174 \times 10^{-5}$ & 1030.3033 & 0.5263 & 122771.551 \\
\hline 140 & $4.3990 \times 10^{-5}$ & 1040.5110 & 0.5141 & 121601.888 \\
\hline 150 & $4.3812 \times 10^{-5}$ & 1050.1521 & 0.5024 & 120422.810 \\
\hline 160 & $4.3641 \times 10^{-5}$ & 1059.3718 & 0.4916 & 119334.382 \\
\hline 170 & $4.3476 \times 10^{-5}$ & 1068.2470 & 0.4811 & 118210.882 \\
\hline 180 & $4.3318 \times 10^{-5}$ & 1076.7219 & 0.4712 & 117122.526 \\
\hline 190 & $4.3159 \times 10^{-5}$ & 1082.2191 & 0.4618 & 115797.117 \\
\hline 200 & $4.3008 \times 10^{-5}$ & 1092.7255 & 0.4528 & 115045.132 \\
\hline 210 & $4.2859 \times 10^{-5}$ & 1100.2758 & 0.4442 & 114034.977 \\
\hline 220 & $4.2713 \times 10^{-5}$ & 1107.5725 & 0.4357 & 112979.500 \\
\hline 230 & $4.2574 \times 10^{-5}$ & 1114.7008 & 0.4276 & 111957.077 \\
\hline 240 & $4.2435 \times 10^{-5}$ & 1121.5057 & 0.4201 & 111043.203 \\
\hline 250 & $4.2299 \times 10^{-5}$ & 1128.0712 & 0.4127 & 110062.881 \\
\hline 260 & $4.2170 \times 10^{-5}$ & 1134.4849 & 0.4055 & 109090.260 \\
\hline 270 & $4.2041 \times 10^{-5}$ & 1140.7148 & 0.3988 & 108207.954 \\
\hline 280 & $4.1915 \times 10^{-5}$ & 1146.7823 & 0.3860 & 105616.693 \\
\hline 290 & $4.1793 \times 10^{-5}$ & 1152.6270 & 0.3857 & 106373.850 \\
\hline & & & & \\
\hline & & & \\
\hline
\end{tabular}

Table 9.1 (a).Various flow parameters at each nozzle segment $\mathrm{n}$ Table. 9.1 (b). Various flow parameters at each nozzle segment 


\section{VARIATION OF PROPERTIES ALONG THE NOZZLE}
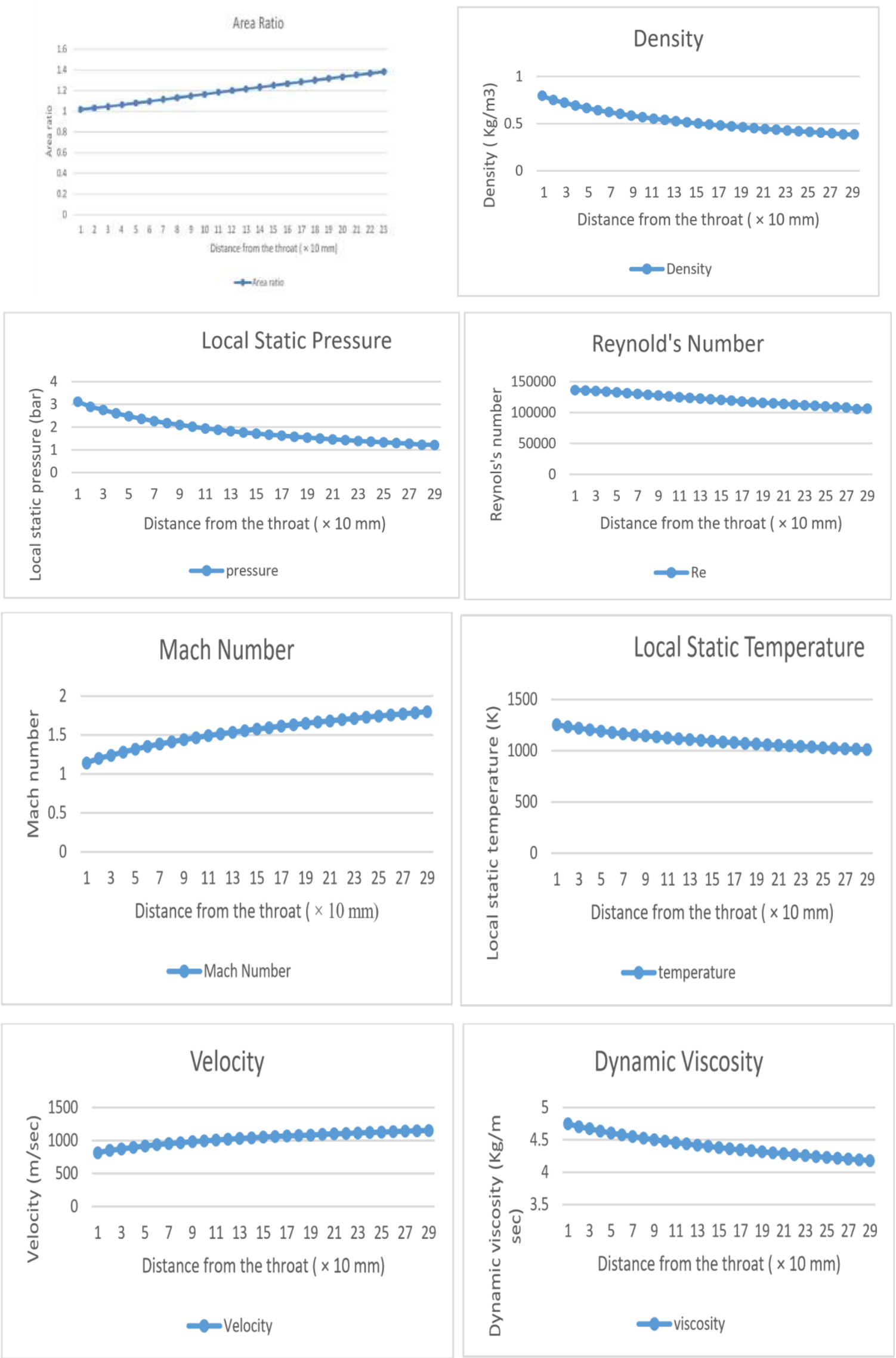


\section{SHEAR STRESS CALCULATION}

The Reynold's number at nozzle exit is given by,

Renozzle exit $=\operatorname{Re} 1+\operatorname{Re} 2+\operatorname{Re} 3+\ldots \ldots \ldots \ldots \ldots \ldots+\operatorname{Re} 29$

By using the Reynold's number values at each segment, $R_{\text {enozzle exit }}=3507797.147$

Now, The Reynold's number at plate centre is given by, $R_{\text {eplate centre }}=\rho$ nozzle exit ${ }_{\mu} \times$ Vnozzle exit $\times 12+$ Renozzle exit

nozzle exit

Where, $\rho_{\text {nozzle exit }}=$ Density at nozzle exit $=0.3875 \mathrm{Kg} / \mathrm{m}^{3} \mathrm{~V}_{\text {nozzle exit }}=$ Velocity at nozzle exit $=1152.627 \mathrm{~m} / \mathrm{sec} \mu_{\text {nozzle exit }}$ $=$ Dynamic viscosity at nozzle exit $=4.1793 \times 10^{-5} \mathrm{Kg} / \mathrm{m} \mathrm{sec}, \quad$ thus, $\mathrm{R}_{\text {eplate centre }}=4.1490 \times 10^{6}$

Calculation of skin friction coefficient $\left(\mathrm{C}_{\mathrm{fx}}\right)$ :- $\mathrm{C}_{\mathrm{fx}}=0.0591 \mathrm{R}_{\mathrm{ex}}{ }^{-0.2}\left\{5 \times 10^{5}<\mathrm{R}_{\mathrm{e}}<10^{7}\right\}=2.81017 \times 10^{-3}$

[From Heat and mass transfer data book by S.M Yahya]

Calculation of shear stress $(\tau):-\tau=\mathrm{C}_{\mathrm{fx}} \times 1 / 2 \times \rho_{\text {nozzle exit }} \times \mathrm{V}^{2}$ nozzle exit $=719.9955 \mathrm{~N} / \mathrm{m}^{2}$

\section{FINDING TEMPERATURE PERFORMANCE OF THERMAL BARRIER COATING}

In order to check the performance of the thermal coating the temperature of the bare plate in the supersonic flow is calculated and compared with the plate coated with TBC.

12.1 Tests conducted: - Test No. 1:-

Specimen : Mild Steel bare plate,

Size: $120 \mathrm{~mm} \times 100 \mathrm{~mm}$,

Thickness : $3 \mathrm{~mm}$

- K-type thermocouples are installed at the bottom of the bare M.S. plate as shown in figure 12.1.

- Then this plate is kept in the flow using the plate holder as show in the figure.

- Once the fluid flow is started, the flow passes over the bare M.S. plate at a temperature of 1009.5 K. $\square$ The visual conditions of the plate before and after the test is shown in the figure 12.2.

- The temperature at the bottom surface of the plate is measured by using type ' $\mathrm{K}$ ' thermocouples.
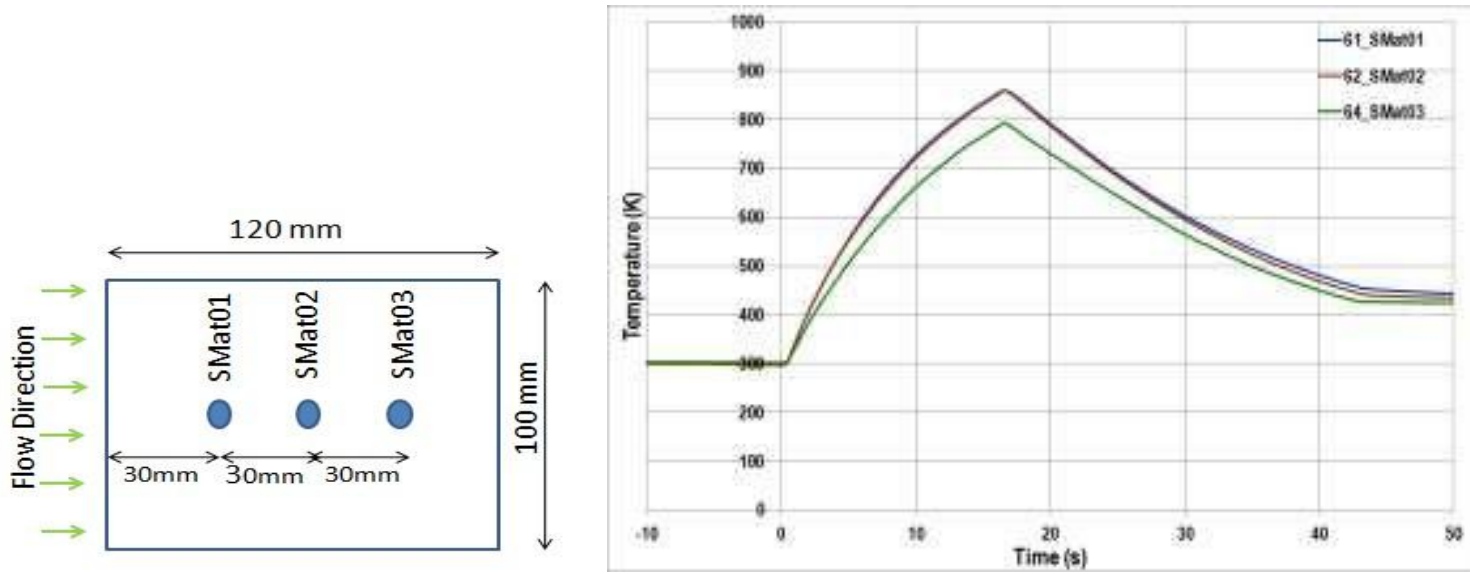

Fig.12.1.Location of type ' $\mathrm{K}$ ' thermocouples bonded to the plate.

Fig.12.3.Back wall temperature specimen-1,

Mild Steel bare plate, $3 \mathrm{~mm}$ thickness. Figure 12.3 shows the back wall temperature for the bare Mild Steel plate, $3 \mathrm{~mm}$ thick. Figure 12.2 (a) and 12.2 (b) show the condition of the specimen before and after the test. The discoloration of the plate is seen in the test.
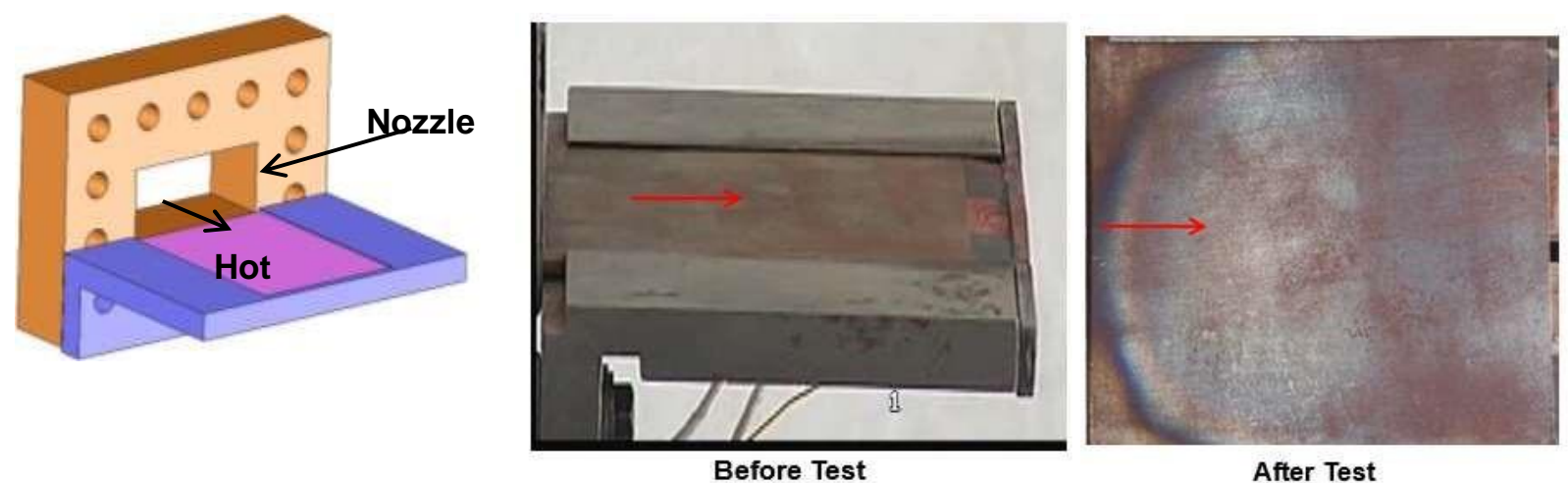

After Test

12.1(a).Mild Steel bare plate before the test

12.2(b).Mild Steel bare plate after the test 


\section{Observation test no.1:-}

1. Test duration is approximately 16 seconds.

2. Maximum temperature reached is $834.3 \mathrm{~K}$ by SMat01 at the end of $16^{\text {th }}$ second.

3. Thermocouples SMat02 are reading almost identical and responding in a similar way. Thermocouple SMat03 is also reading in similar way but temperature recorded is lesser than SMat01 and SMat02.

4. This test will be base for comparing the performance of TBC coating testes subsequently.

\section{Test No. 2:-}

Specimen: TBC coating, Size: $120 \mathrm{~mm} \times 100 \mathrm{~mm}, \quad$ Thickness: TBC coating, $2 \mathrm{~mm}$ and M.S. plate substrate $3 \mathrm{~mm}$

$\square$ The TBC coating is applied to another test specimen of same material of bare plate and rest all conditions were same as conditions set during bare plate.

\section{Observation test no. 2:-}

1. Temperature recorded at the back wall of specimen at the $16^{\text {th }}$ second of test duration by SMat01, SMat02, SMat03 are $327 \mathrm{~K}, 323 \mathrm{~K}$ and $326 \mathrm{~K}$ respectively. These all values are approximately equal.

2. Temperature reduction of approximately $500 \mathrm{~K}$ at $16^{\text {th }}$ second of operation is measured with respect to bare plate at SMat01 and SMat02.

3. Mild erosion is seen in the coating.

4. Sufficient thickness of TBC material is observed on the specimen after the test.

12.2 Test results: After measuring the temperature values at the bottom side of the plates, the graphs (Temperature vs Time) are plotted as shown in figure 12.3 and figure 12.5. The maximum temperature reached in bare M.S. plate is $834.3 \mathrm{~K}$ whereas, the maximum temperature reached in the plate coated with TBC is $327 \mathrm{~K}$. Temperature reduction of approximately $500 \mathrm{~K}$ is achieved in the plate coated with TBC as compared to the bare plate.

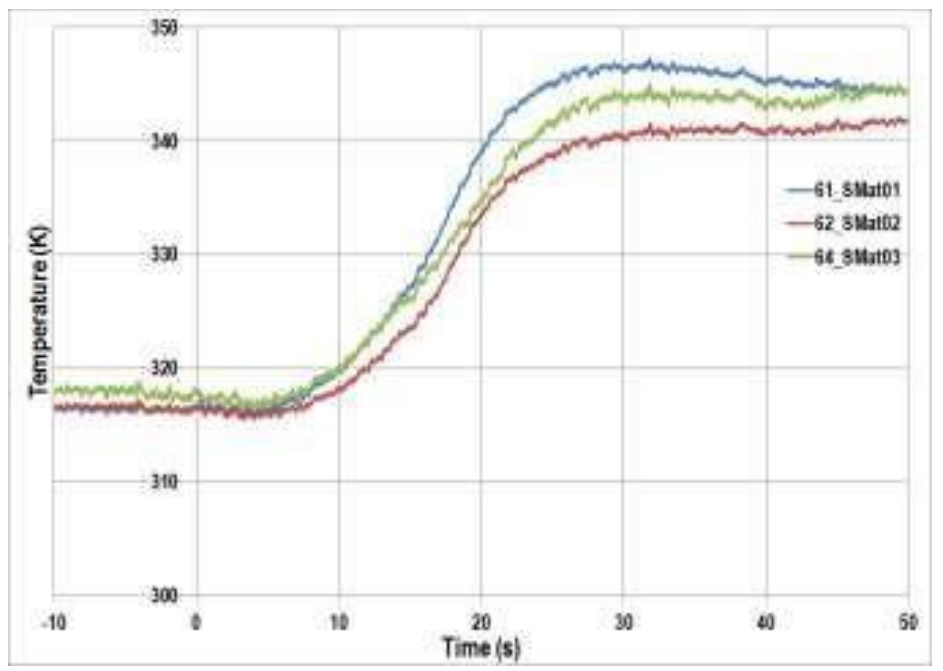

Fig.12.5.Back wall temperature specimen-2, TBC coating, $2 \mathrm{~mm}$ thickness
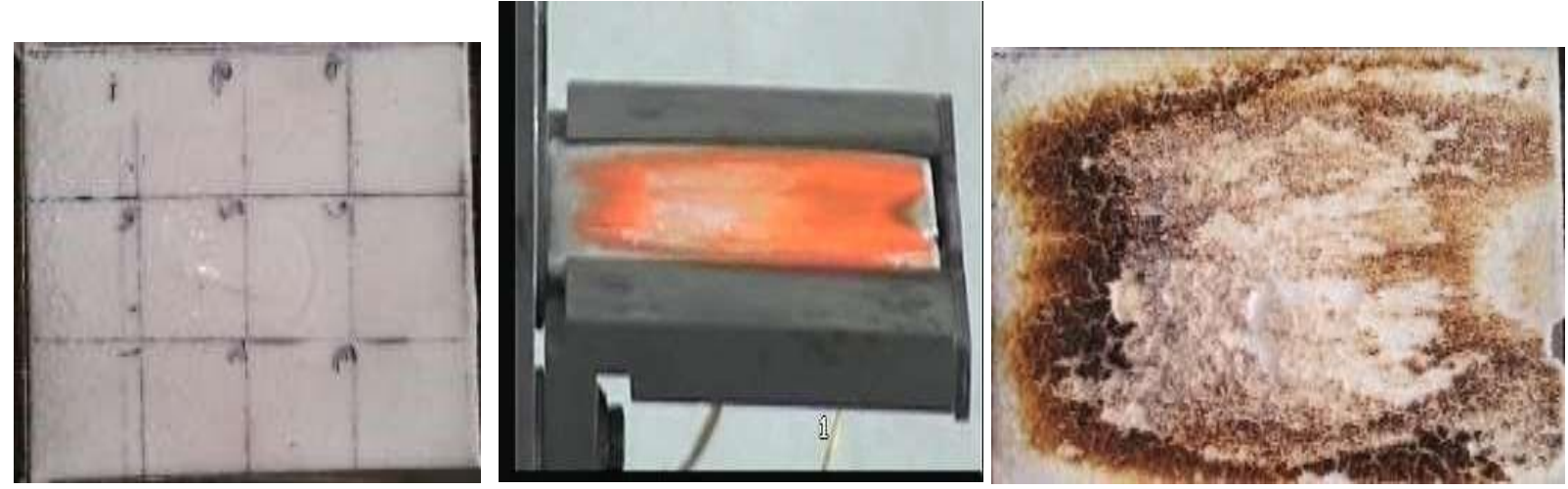

Fig.12.4 (a).Before test Fig.12.4 (b).During test Fig.12.4 (c).After test 


\section{CONCLUSION}

The Thermal Barrier Coating was successfully tested at Scram Test Facility under high temperature supersonic flow conditions.

Temperature reduction of approximately $500 \mathrm{~K}$ was achieved in the Mild Steel plate coated with TBC as compared to the bare M.S. plate. The Thermal Barrier Coating can successfully withstand maximum shear stress of about $720 \mathrm{~N} / \mathrm{m}^{2}$ at exit flow temperature of $1009.5 \mathrm{~K}$. Sufficient thickness of TBC material was observed on the specimen after the test. The coating did not vanish completely during the 16 seconds of test duration and maintained sufficient thickness after the test. Thus, this missile coating is suitable for the application in supersonic missiles since, a supersonic missile undergoes a wide range of temperature changes during its course. This missile coating can effectively protect missile components and its payload from excessive heat generated due the aerodynamic heating of missile surface while maintaining sufficient thickness for longer period of time.

\section{REFERENCES}

1. Heat and Mass Transfer data book by S. M. Yahya.

2. http://www.engineeringtoolbox.com

3. Gordon, S \&Mebride, M.J, computer program for calculation of complex chemical equilibrium composition, Rockets performance, Incident \& reflected shocks and chapman - Jouguet donations a report, NASA -SP-273.

4. Fundamentals of Aerodynamics by J.D Anderson.

5. http://www.flowmeters.com/turbine-technology

6. http://www.omega.com/manuals/manualpdf/M4517.pdf

7. http://www.instrumentationtoday.com/pressure-transducer/2011/09/

8. http://naca.central.cranfield.ac.uk/reports/1958/naca-report-1381.pdf

9. http://www.thermocoupleinfo.com

10. http://www.documentation.emersonprocess.com/groups/public/documents/bulletins/debul2008x012.pdf

11. http://www.eetindia.co.in/ARTICLES/2007NOV/PDF/EEIOL_2007NOV16_TEST_SIG_TA.pdf?SOURCES=DOWN LOAD

12. http://www.sensorland.com 